\title{
ANDRÉ GORZ, PELA INCONDICIONALIDADE DA RENDA ${ }^{1}$
}

\author{
Françoise Gollain*
}

\begin{abstract}
André Gorz partilhou com defensores da renda de existência o diagnóstico segundo o qual o atual sistema de redistribuição não está adaptado à flexibilidade e à precarização do emprego como um dado estrutural de mercado de trabalho. Entretanto, além do desejo de remediar essas disfunções e de assegurar uma seguridade existencial a cada um, ele concebia a outorga de uma renda garantida a todos como um dos instrumentos de uma transformação radical e emancipadora. Nessa perspectiva, a renda de existência está articulada a duas séries de medidas: redução do tempo de trabalho e expansão das atividades autônomas. O exame do lugar acordado a cada um dos termos desse tríptico permite perceber a significativa mudança de Gorz para um degrau mais elevado da incondicionalidade da renda. Para além dessa virada, buscamos ressaltar a permanência de seu projeto político (e filosófico) fundamental: restringir as relações mercantis e avançar para uma sociedade caracterizada por formas de cooperação não mercantis.
\end{abstract}

Palavras-chave: André Gorz, Existencialismo. Incondicionalidade da renda.

\section{INTRODUÇÃO}

Partilhando com numerosos defensores da renda de existência (RE) o diagnóstico segundo o qual o atual sistema de redistribuição não está adaptado à flexibilidade e à precarização do emprego, que constituem um dado estrutural do mercado de trabalho, Gorz almejava remediar essas disfunções, manter uma seguridade existencial, e conceber a outorga de uma renda garantida a todos como um dos instrumentos de uma transformação social radical e emancipatória. Contrariamente a numerosas discussões que ainda abordam essa reivindicação da garantia de renda de maneira isolada, para o autor, ela está necessariamente articulada a duas séries de medidas: alcançar uma melhor partilha do trabalho social entre todos e promover uma verdadeira multiatividade, compreendendo uma proporção crescente de atividades que ele qualificou como "autôno-

* The Open University.

PO Box 197. Milton Keynes. MK7 6BJ. United Kingdom. fgollain@yahoo.co.uk

${ }^{1}$ Traduzido do francês por Josué Pereira da Silva. Publicação original: "André Gorz, vers l'inconditionnalité du revenu", L'Économie politique, 67, juillet 2015, p. 52-64. mas”. O exame do lugar acordado a cada um dos termos desse tríptico - renda de existência, redução do tempo de trabalho, expansão das atividades autônomas - permite-nos demonstrar a mudança significativa da visão de André Gorz para um degrau mais elevado da incondicionalidade da renda de existência na segunda metade dos anos 1990. Dedicamo-nos, não obstante, a realçar a identidade de seu projeto político (e filosófico) fundamental para além desse giro importante: restringir as relações mercantis e avançar para uma sociedade caracterizada pelo primado de formas de cooperação não mercantis.

A promoção ativa por Gorz da renda de existência se inscreve no quadro de uma filosofia sartriana da liberdade ${ }^{2}$ e foi inspirada pelos textos mais visionários de Marx, notadamente os Grundrisse. ${ }^{3}$ Ele retoma a tese marxiana segundo a qual o desenvolvimento das forças produtivas e, em particular, o aumen-

${ }^{2}$ Para uma abordagem inicial de sua obra, ver Fourel \& Gollain (2013); Fourel (2012), Gollain (2014), Gorz (2008) (conjunto de textos que ele mesmo selecionou); Gorz (2015) (textos inéditos em francês apresentados por Willy Gianinazzi)

${ }^{3}$ Ou Manuscrits de 1857-1858, La Dispute/Editions Sociales, 2011. 
to dos ganhos de produtividade ligado àquilo que denominou revolução "microeletrônica", depois "informacional", engendra uma redução inexorável do número global de horas trabalhadas. Mas o fato de toda mutação tecnológica ter historicamente sido seguida de um crescimento da demanda, e, portanto, da produção, tendo por consequência compensar largamente os efeitos sobre o emprego dos ganhos de produtividade ${ }^{4}$, não significa que isso seja desejável em termos ecológicos e como desenvolvimento individual. A própria lógica do capitalismo - aquela de uma dinâmica de crescimento infinito - impede-o de responder, em termos emancipatórios, a essa eliminação progressiva do trabalho humano do processo de produção. Cabe, pois, a um movimento verdadeiramente socialista apoderar-se desse processo e torná-lo instrumento de uma sociedade de tempo liberado, tudo isso em ruptura profunda com a valorização do trabalho e da produção que impregnou as tradições operária e marxista.

Essa tomada de posição resolutamente antiprodutivista conduziu-o a formular a combinação de RE, redução do tempo de trabalho (RTT) e atividades autônomas, como a peça mestra de uma utopia ecossocialista que responde à dupla preocupação com a equidade e com a autolimitação das necessidades సे. (Gollain, 2014).

\section{DISTRIBUIR A RENDA E DIVIDIR O TRABALHO: crítica da alocação universal}

Compreendemos, então, que ele estigmatizou a "versão de direita" da renda garantida, após sua primeira expressão sob a revolução industrial na Grã-Bretanha com a experiência da Speenhamland de $1795,{ }^{5}$ pela qual se tratava de tornar socialmente tolerável uma

${ }^{4}$ Objeção dirigida por Denis Clerc (Gorz, 1984).

${ }^{5}$ Da paróquia do mesmo nome, na qual se concedia aos mais pobres um complemento de renda estabelecido em função do número de filhos e do preço dos cereais. extensão da indigência. Na esteira de Milton Friedman ${ }^{6}$ nos Estados Unidos, a preferência dos liberais foi a de se desembaraçar do burocratismo do Estado providência e geralmente dos entraves ao livre jogo do mercado de trabalho para o qual se podia encontrar um equilíbrio dito natural. Como o jogo da oferta e da demanda não garantia um salário suficiente, preconizou-se um sistema de imposto negativo, que autoriza os empregadores a gerir a mão de obra com uma flexibilidade máxima. ${ }^{7}$

A partir da publicação de Adeus ao Proletariado em 1980, André Gorz sustenta que a outorga de um verdadeiro "salário cidadão" implicaria reconhecer que, com o impulso dos meios científicos e técnicos, a quantidade de trabalho fornecida por cada um de nós pouco tem a ver com a quantidade de riquezas produzidas,o que é cada vez mais difícil de mensurar.

O montante de renda deve, em consequência, ser dissociado da duração do trabalho fornecido individualmente. Nessa perspectiva, uma RE de esquerda deveria ser a remuneração - seja adiantada, seja diferida - da participação de cada cidadão no processo social de produção.

Três anos mais tarde, Les Chemins $d u$ paradis apresenta uma reflexão sobre as condições práticas de sua implementação. Ali, Gorz (1983a) preconiza retornar ao que era a norma no início do século XVIII, ou seja, a uma duração média do trabalho assalariado de 1000 horas por ano, correspondendo a cerca de 20 mil a 30 mil horas durante uma vida. ${ }^{8}$ Ele propõe um sistema de tiragem pelo qual a cada período de trabalho correspondia certo número

${ }^{6}$ Capitalisme et Liberté, Editions A contre-courant, 2010 [1962].

${ }^{7}$ Um imposto negativo foi aventado na França, no início dos anos 1970, por dois conselheiros de Valéry Giscard d'Estaing, Lionel Stoleru e Christian Stoffaës.

${ }^{8}$ Corresponde a 10 ou 15 anos em tempo integral. Ele se baseava, à época, em uma RTT anual em torno de 3\% para atingir 900 horas de trabalho por ano ao fim do século XX. Depois, em 1989, ele se dedica a um exame detalhado de vários cenários possíveis de RTT em função de diferentes variáveis: crescimento, ganhos de produtividade, salários, desemprego (Gorz, 1991, p. 185-214). 
de pontos que, em seguida, daria direito a um período dado de não trabalho pago. À medida que a parte do salário direto tende a se reduzir, a função da RE é assegurar, de maneira crescente, a distribuição das riquezas socialmente produzidas. Seu financiamento repousaria num imposto sobre o consumo do tipo TVA, ${ }^{9}$ que incide nos preços em função de prioridades sociais e ecológicas. Paralelamente, Gorz imagina, já nessa época, a adoção de diferentes tipos de moeda, que não podem ser entesouradas, destinados às trocas de serviços locais. Ele insistirá, até o fim, sobre a necessidade de políticas adaptadas em matéria de educação, de formação, de urbanismo e de organização do território, assim como de uma política fiscal reelaborada para fazer da RE um dispositivo liberador. A RTT deverá resultar da elaboração de objetivos diferenciados, segundo os diferentes ramos de atividade, em função de suas necessidades de mão de obra. Consequentemente, a passagem a uma verdadeira renda social será progressiva, mas ela permitirá avançar para uma sociedade menos organizada em torno do trabalho assalariado.

Entretanto, a afirmação de uma relação de reciprocidade entre direito à renda e direito ao trabalho, combinada com um dever de trabalhar, assim como a centralidade da temática da redução voluntária do tempo de trabalho "[...] trabalhar menos para todos trabalharem e se ativarem por eles mesmos" (Gorz, 1980, p. 11) - separaram a versão gorziana inicial de outros cenários de esquerda, tais como aqueles dos cristãos-sociais, ou dos libertários, que reivindicavam uma alocação universal e afirmavam um direito econômico baseado numa cidadania não fundada na participação no processo de produção.

Com efeito, Gorz rejeitava ferozmente, no curso desse primeiro período, o princípio de uma desconexão entre a renda e o trabalho em si mesmo. Essa desconexão parecia-lhe reduzir a solidariedade a um assunto fiscal e institucionalizava a desconexão para tornar ${ }^{9}$ Imposto sobre valor agregado. N. do T. tolerável a dualização entre economia e sociedade. O trabalho, no sentido econômico do termo, faz-se objeto de uma troca mercantil na esfera pública. Por consequência, ele afeta os indivíduos não somente no que se refere a uma utilidade, mas igualmente no que diz respeito ao pertencimento e ao reconhecimento sociais. Portanto, é na medida em que o trabalhador não estabelece relações pessoais e privadas com seus empregadores ou seus clientes que ele é fator de emancipação. Em outros termos, o trabalho remunerado insere-o, como indivíduo social, em geral, no circuito das trocas econômicas e sociais e contribui, assim, para combater o fechamento da esfera privada (particularmente para as mulheres).

Em outras palavras, qualquer que seja o nível das técnicas, trabalhar é uma necessidade inerente a toda sociedade e "ninguém deve portar o fardo da necessidade por conta dos outros e ninguém, portanto, deve ser dispensado de carregar sua parte" (Gorz, 1991, p. 176); isso seria contrário ao espírito de justiça numa sociedade não escravista. Convém, então, reparti-lo equitativamente, de maneira a que o pertencimento e a passagem contínua entre as duas esferas da sociedade, a do trabalho autônomo ou assalariado e a das atividades autônomas, previnam contra a segregação social e favoreçam o desenvolvimento individual. Essa representação dicotômica dos espaços e tempos sociais se reporta, especificamente, à oposição estabelecida por Marx entre esfera da necessidade e esfera da liberdade, cuja correspondência Gorz percebeu em Ivan Illich: uma esfera da heteronomia distinta e aquela da autonomia. A segunda é constituída de atividades que trazem em si mesmas seu próprio fim, na medida em que elas têm "um caráter facultativo, não mercantil e não econômico” (Gorz, 1987, p. 36).

Como veremos agora, a posição de André Gorz sobre a renda garantida vai, em seguida, evoluir em resposta a duas mutações maiores do trabalho: o impacto da revolução digital assim como a degradação contínua da relação salarial. 


\section{PELA INCONDICIONALIDADE}

Na segunda metade dos anos 1990, a redução do tempo de trabalho como alavanca de uma saída da sociedade salarial passa ao segundo plano de sua política (de liberação) do tempo. Gorz afirma que uma problemática de redução do tempo integral semanal ou anual já não é pertinente para os trabalhadores independentes e mesmo para os cada vez mais numerosos trabalhadores temporariamente desempregados. No início dos anos 2000, ele constata que a precariedade crescente do emprego anulou o potencial liberador da política de RTT na França. A contração do volume anual total de trabalho ocasionado pelas leis Aubray conferiu um controle do tempo, não aos assalariados, mas aos empregadores. Nesse contexto, ele é levado a colocar, de forma crescente, a ênfase sobre uma necessária permanência da renda como condição indispensável de uma autonomia existencial e continua a denunciar a falta de sentido da valorização do trabalho a qualquer preço.

Trata-se, ao contrário, de articular o sentido potencialmente liberador das contradições e dificuldades presentes: a "busca de sentido" (1988) que atravessa seus escritos testemunha sua relação não determinista no que సิ se refere à evolução histórica. A possibilidade de mudança reside numa inversão do sentido, reitera ele com a publicação de Misères du pré\& sent: richesse du possible: à medida que a

[...] figura central do precário é [...] potencialmente a nossa; é a ela que se trata de civilizar e de reconhecer no duplo sentido da palavra para que, da condição de submetida, ela possa se tornar um modo de vida escolhido, desejável, socialmente controlado e valorizado, fonte de culturas, de liberdades e de socialidades novas; para que ela possa se tornar o direito para todos de escolher as descontinuidades de seu trabalho sem se submeter à descontinuidade de renda (Gorz, 1997, p. 90).

A partir desse momento, Gorz critica as medidas que têm como efeito aumentar a condicionalidade da renda social. Ele toma po- sição contra o workfare pregado inicialmente pelos neoliberais da Escola de Chicago e colocado em prática pelo governo Clinton, depois progressivamente em países da Europa, que consiste no acúmulo de uma renda de base e de uma renda do emprego assalariado, cuja remuneração é igualmente insuficiente. Dentro desse espírito, ele ataca diversas políticas europeias que obrigam o candidato a um emprego a aceitar uma série de formações que substituem o verdadeiro emprego que a sociedade é incapaz de lhe fornecer, mas cuja função é perpetuar a ficção de uma incapacidade de empregabilidade dos interessados.

De maneira assaz significativa, ele igualmente estigmatiza o princípio da outorga de uma renda de base em contrapartida ao cumprimento de atividades benevolentes, como é preconizada por Ulrich Beck ou Claus Offe na Alemanha, ou ainda pelo norte-americano Jeremy Rifkin, assim como pelo relatório Boissonnat, publicado pelo Commissariat général du plan ${ }^{10}$, que propunha o cumprimento de trabalho obrigatório no terceiro setor. Gorz considerava esse projeto a ilustração perfeita da vontade do Capital e do Estado de controlar o tempo liberado do trabalho e de administrá-lo como prolongamento funcional da vida de trabalho. Não somente as atividades desinteressadas perdem, assim, seu sentido, mas ainda "a condicionalidade transforma a renda de base em salário, o benevolato em quase emprego" (Gorz, 1998, p. 35).

Gorz se junta, finalmente, aos partidários de fórmulas contra as quais ele anteriormente se resguardava, ${ }^{11}$ defendendo doravante a atribuição da "[...] alocação universal e incondicional de uma renda básica acumulável com o rendimento de um trabalho." (Gorz, 1997, p. 140).

${ }^{10}$ Le Travail dans vingt ans, La Documentation française (Boissonnat, 1995).

${ }_{11}$ Notadamente Alain Caillé, diretor de La Revue du MAUSS, Jacques Robin, animador da revista Transversales sciences/cultures, assim como Philippe Van Parijs, membro da BIEN (Basic Income European Network, tornada em 2004, Basic Income Earth Network). Conforme Van Parijs apud Fourel (2012) e Caillé e Fourel (2013). 
Mais precisamente, essa RE, independentemente da ocupação de um emprego, só pode se tornar emancipadora sob a condição de ser: 1) verdadeiramente incondicional, "pois somente a sua incondicionalidade poderá preservar a incondicionalidade das atividades que apenas têm sentido caso forem cumpridas por si mesmas" (Gorz, 1997, p. 144); suficiente, porque, caso contrário, ela teria por efeito incitar a uma busca constante de emprego de má qualidade - devido à desregulamentação e à degradação geral da relação salarial -, em lugar de permitir uma arbitragem entre uso mercantil e não mercantil do tempo (nenhum montante é, todavia, indicado);2) atrelada a verdadeiras possibilidades de autoprodução, sob pena de não ser mais que um salário da inatividade forçada.

Precisaremos, adiante, os motivos dessa reviravolta concernente ao caráter incondicional da RE.

\section{A VIRADA DO IMATERIAL}

A consideração contínua do impacto da revolução informacional sobre as mutações do trabalho incitou André Gorz a subscrever a tese da passagem a um "capitalismo imaterial", ou ainda "capitalismo cognitivo"12, coerente com as previsões de Marx (2011) que, nos Grundrisse, antecipa a mutação atual do capitalismo: "O desenvolvimento do capital fixo indica a que grau o saber social geral, o conhecimento, tornou-se força vital produtiva imediata e, por conseguinte, até que ponto as condições do processo vital da sociedade [são] elas próprias passadas ao controle do intelecto geral”.

Com a mutação pós-fordista, as atividades geradoras de valor para o capital requerem não somente os conhecimentos formais, uma

${ }^{12}$ Sobre a corrente do mesmo nome reunida em torno das revistas Futur antérieur, depois Multitudes, Cf. Gollain, 2010. Citamos, entre outros, Jean-Marie Vincent, Antonio Negri, assim como Carlo Vercellone com quem as convergências são numerosas. Cf. Vercellone in Fourel, 2012 e Caillé \& Fourel, 2013. troca e uma gestão de fluxos de informações, mas também os saberes informais e competências pessoais dos indivíduos, como a aptidão a colaborar, a criatividade, etc. - tudo que, para Gorz, participa da "produção de si". A autonomia é, doravante, instrumentalizada, colocada a serviço da empresa, pois a prescrição delimitada ao lugar e ao tempo de trabalho tende a ser substituída por uma prescrição de toda a subjetividade. De outra parte, o caráter cada vez mais central dessa "inteligência coletiva" confirma seu diagnóstico emitido uma quinzena de anos antes: o tempo de trabalho visível ou imediato é ínfimo em relação àquele que é consagrado a produzir conhecimentos, saberes e competências mais amplas da força de trabalho. Com a criação de riquezas mercantis distribuindo cada vez menos salários, é preciso que essas riquezas sejam repartidas de outra forma: uma alocação incondicional "[...] é a melhor e a mais adaptada a uma evolução que torna o nível geral dos conhecimentos, knowledge, a força produtiva principal" (Gorz, 1997, p. 144).

A adesão tardia de Gorz à incondicionalidade da RE testemunha, em realidade, uma coerência vis- à- vis suas opções mais fundamentais anunciadas a partir dos anos 1980: dentro desse novo contexto, face ao terreno ganho pelas lógicas mercantis e burocráticas, assim como ao nível da existência cotidiana e das atividades econômicas, ele respondeu exigindo um patamar mais importante de incondicionalidade na produção - produção de si, de bens e de serviços -, atualizando sua concepção das atividades autônomas.

Essa concepção extensiva da incondicionalidade decorre de uma tomada de posição antifuncionalista e antieconomicista.

Herdeiro de Edmund Husserl e da Escola de Frankfurt, ele se diz dedicado a revelar "[...] o sentido irracional da racionalização econômica, a desrazão da razão instrumental, a aplicação do cálculo, da quantificação, da busca de rendimento máximo às atividades, cujo sentido ela anula ou perverte" (Gorz, 2015, p. 33). Ao argumentar que o sentido profundo 
das metamorfoses atuais do trabalho reside na liberação do tempo, permitida pelo desenvolvimento dos ganhos de produtividade, Gorz dirigiu notadamente uma crítica veemente ao desenvolvimento dos serviços à pessoa por meio de uma extensão ilegítima do princípio da racionalidade. Apresentado como um "jazigo do emprego", esse novo setor repousa na cisão entre uma transbordante minoria ocupando os empregos estáveis e o número crescente de serviçais mal pagos a quem os primeiros se subempregam, em atividades que deveriam constituir o "trabalho para si"; ou seja, atividades através das quais nós nos apropriamos de nosso corpo e de nossa existência (cozinhar, cuidar da higiene, se ocupar das crianças, levar o cachorro a passear, etc.).

De uma maneira geral, sua tardia adesão à alocação universal repousa no argumento ético-filosófico que já fundamentava, em primeira versão, sua política do tempo: contra o "paneconomismo", ele firma o caráter insuperável da dicotomia entre uma lógica econômica que, justamente, tem em vista economizar - o tempo, entre outros - e uma lógica de vida que preside a um dispêndio de tempo que tem como fim ele próprio. "Em lugar da 'economia dual'13, é preciso querer o estreitamento da esfera do econômico e a expansão máxima do domínio onde o cálculo econômico não tem lugar pela simples razão de que o tempo ali não é escasso, sendo ele próprio o tempo da vida" (Gorz, 1987, p. 36), adiantava Gorz já em 1987. Uma década depois, ele insiste: à medida que, com o advento do capitalismo cognitivo, a fronteira entre trabalho क e não trabalho se esfuma do ponto de vista do i. ने

${ }^{13}$ Esse termo, utilizado nos anos 1980, remete à cisão da economia em dois setores: o setor competitivo, de um lado, e aquele dos "pequenos trabalhos", de outro.
[...] mesmo que atividades cujos fins são elas mesmas não sejam meio para qualquer outra coisa. A cooperação produtiva não é nem jogo, nem prática gratuita de uma arte. A interação e a comunicação têm nela um sentido fundamentalmente diferente daquele que tem em um balé, uma equipe esportiva, um debate político ou um diálogo amoroso. Não é por serem mais produtivos que os sujeitos desenvolvem suas faculdades nessas últimas atividades. É porque eles as desenvolvem ali, que a produtividade de sua força de trabalho aumenta (Gorz, 1998, p. 33).

Essa é a razão pela qual, em sua argumentação, não se trata mais agora de remunerar os indivíduos em virtude de sua contribuição sob as diversas formas à sociedade (mesmo fora da empresa), mas, ao contrário, de sustentar o desenvolvimento de "individualidades ricas" (Marx) irredutíveis à sua função produtiva. André Gorz distingue duas concepções de renda de existência: "aquela que vê nela o meio de subtrair a vida ao imaginário mercantil e ao trabalho total, e aquela que, ao contrário, vê nela uma remuneração do tempo fora do trabalho, cuja contribuição à produtividade do trabalho tornou-se decisiva" (Gorz, 2003, p. 30). Sua preferência pela primeira concepção denota um antiutilitarismo radical: "[...] liberando a produção de si, dos constrangimentos da valorização econômica, a renda de existência deverá facilitar o pleno desenvolvimento incondicional das pessoas para além do que é funcionalmente útil à produção" (Gorz, 2003, p.31). Seu valor heurístico é apontar para uma sociedade de cultura e não mais de trabalho, uma sociedade de um tempo livre, pleno de sentido, na qual cada um poderá se ativar e não trabalhar.

\section{RENDA DE EXISTÊNCIA CONTRA CAPITALISMO FINANCEIRO}

Em seus escritos da última década, Gorz retoma as reflexões presentes desde 1983, relativas à redução surpreendente dos custos unitários de produção, ligada ao desenvolvimento das tecnologias da informação: a redução da quantidade de trabalho necessário à produção 
de um volume dado de mercadorias se traduz numa diminuição proporcional de seu valor mercantil. ${ }^{14} \mathrm{O}$ capitalismo não se perpetua a não ser sobre bases fictícias cada vez mais precárias: o desenvolvimento da indústria financeira, assim como uma série de mecanismos de apropriação para assegurar um monopólio, tal como a proliferação de patentes correspondendo à elevação do poder de uma economia da renda, cujas fontes constituem, em realidade, os bens comuns.

Sublinhando a contradição entre valor e riqueza (não econômica), ele põe em relevo as potencialidades oferecidas pela situação presente.

De uma parte, há os bens "comuns" ou "riquezas primeiras”, cujo valor intrínseco e não mercantil - a terra, as sementes, o genoma, os bens culturais, as competências e os saberes pessoais, etc. - não se prestam, fundamentalmente, a uma utilização privativa mercantil. De outra parte, a produtividade, multiplicada pelas técnicas de produção contemporâneas, conduz a uma riqueza social inaudita. Com o advento das tecnologias digitais, é doravante possível, para as comunidades no mundo inteiro, se reapropriarem do trabalho; em outros termos, produzir riquezas verdadeiras (diferenciadas das mercadorias), resultantes de atividades realmente autônomas, segundo uma lógica que encontra sua figura exemplar no modelo cooperativo e não mercantil do software livre.

É, finalmente, na perspectiva de "uma economia da gratuidade”, isto é, dentro da qual predominam a produção e o consumo fundados na reciprocidade e na partilha, que ele vislumbrou a atribuição de uma renda garantida, de maneira a "abrir uma brecha" pela qual se poderia preparar "um êxodo da sociedade do trabalho e da mercadoria” (Gorz, 2007). Isso, conforme alertava, com a condição de deixar o terreno da economia para se colocar no da an-

${ }^{14}$ Influenciado pela corrente marxista da "crítica do valor", particularmente Robert Kurz e Moishe Postone. A página HTTP://palim-psao.over-blog.fr de Anselm Jappe, representante francês da corrente "crítica do valor", é um tieconomia. "A reivindicação de uma renda suficiente deve marcar a importância crescente, virtualmente preponderante, dessa outra economia criadora de riquezas intrínsecas, nem mensuráveis, nem intercambiáveis" (Gorz, 2003, p. 100). Dito de outra forma, “... pensada até o limite de suas implicações, a alocação universal de uma renda social suficiente equivale a uma partilha das riquezas socialmente produzidas" (Gorz, 1997, p. 148).

Dentro dessa perspectiva, essa renda não decorre de uma lógica redistributiva, mas deve ser entendida como renda primária. A RE poderia tomar a forma de uma moeda de distribuição teorizada por Jacques Duboin, ${ }^{15}$ sugeria ele, cada vez mais convencido de que uma moeda de consumo específica, "[...] criada e distribuída segundo critérios políticos [...] pode evitar a implosão de um sistema de meios de pagamentos" (Gorz, 2003, p. 56).

\section{PENSAR NO LONGO PRAZO}

Embora a RE permaneça, por si mesma, imanente ao capitalismo, André Gorz sempre adiantou, no entanto, que é preciso reivindicá-la dentro de uma perspectiva que transcenda o sistema. A veia libertária que marca sua obra é, evidentemente, reforçada em suas últimas reflexões, mantendo uma distância crítica de sua parte em relação aos debates detalhados e concretos nos quais ele participou ativamente, tanto na Alemanha, quanto na França, até a metade dos anos 1990:

Eu não penso que a renda de existência possa ser introduzida gradual e pacificamente por uma reforma decidida 'do alto' [...] [a nova moeda] será criada 'de baixo', carregada por uma onda profunda, ao mesmo tempo em que as redes de cooperativas comunais de autoprodução (de 'high-tech self-providing', segundo a fórmula de Bergmann ${ }^{16}$ ) em res-

15 Jacques Duboin (1878-1976), pai do "abundancismo". Funda, em 1935, o jornal La Grande Relève; ele desenvolve ali sua concepção de uma "economia distributiva”. Cf. a contribuição de Marie-Louise Duboin-Mon apud Fourel (2012).

${ }^{16}$ Frithjoff Bergmann impulsionou as práticas de autopro- 
posta a uma conjunção de diferentes formas de crise que nós sentimos se agravar; crise de energia e crise monetária seguida do afundamento do sistema de crédito (Gorz, 2008, p. 154).

Em suas últimas análises, ele mantinha sua confiança nas práticas esboçadas por diferentes movimentos alternativos, tais como as experiências cooperativas conduzidas notadamente na Argentina e no Brasil. Ao manter sua posição central no tríptico já apresentado, a extensão das atividades não regidas pela racionalidade econômica, preconizada durante seu primeiro período, se enunciava agora como "a utopia de autoprodução comunal cooperativa”, inspirada pelo ecologista anarquista Murray Bookchin.

Não duvidamos que esse anticapitalismo radicalizado, que não visa apenas a simplesmente delimitar a racionalidade econômica, mas sair inteiramente do mercado, do trabalho-emprego, da mercadoria, possa ser considerado desconcertante e de uma aplicação imediata e problemática por certos tomadores de decisões progressistas, profissionais engajados ou militantes enraizados. A par de sua qualidade visionária, esses escritos são, não obstante, de natureza a alimentar a função essencial da imaginação teórica e política que perspectivas de longo prazo, as questões do curto prazo são sempre conservadoras." (Gorz, 1983b, p. 5).

dução, desde técnicas mais rudimentares até as técnicas digitais, em seus "centros para o novo trabalho", inicialmente entre os desempregados e entre populações empobrecidas nos Estados Unidos.

\section{REFERÊNCIAS}

BOISSONNAT, Jean. Le Travail dans vingt ans, La Documentation française, Editions Odile Jacob, 1995. Disponível em: <https://books.google.com.br/books ?id $=$ WdDU9F6yFR4C\&printsec $=$ frontcover\&hl $=\mathrm{pt}-$ $\mathrm{BR \#} \mathrm{v}=$ onepage\&q\&f $=$ false $>$. Acesso em: 14 nov. 2017.

CAILLÉ, A.; FOUREL, C. (Ed.). Sortir du capitalisme: le scénario Gorz. Lormont: Le Bord de l'Eau, 2013.

FOUREL, C. (Ed.). André Gorz: un penseur pour le XXIe siècle. Paris: La Découverte, 2012.

FOUREL, Christophe; GOLLAIN, Francoise. « André Gorz, penseur de l'émancipation », La Vie des idées , 3 décembre 2013. ISSN : 2105-3030. URL : http://www.laviedesidees. fr/Andre-Gorz-penseur-de-l.html. Acesso em: 12 nov. 2017.

FRIEDMAN, Milton. Capitalisme et Liberté. Paris: Leducs éditions. 2010. [196ㄹ]

GOLLAIN, F. L'apport d'André Gorz au débat sur le capitalisme cognitif. Revue du MAUSS, Paris, v. 35, n. 35, p. 297-314, $1^{\text {er }}$ semestre 2010.

GOLLAIN, F. André Gorz pour une pensée de l'écosocialisme. Neuvy-en-Champagne: Le Passager Clandestin, 2014.

GORZ, A. Adieux au prolétariat. Au-délà du socialisme. Paris: Éditions Galilée,1980.

GORZ, A. Les chemins du Paradis: L'agonie du Capital. Paris: Editions Galilée, 1983a.

GORZ, A. Entretien: Les Chemins du paradis. Alternatives économiques, [S.l.], juil. 1983b, p. 5-6.

GORZ, A. Emploi et revenu, un divorce nécessaire? Entretien avec Denis Clerc. Alternatives économiques, [S.l.], p. 15-17, juil. 1984.

Gorz, A. Allocation universelle: version de droite et version de gauche. Revue du MAUSS, Paris, n. 22, p. 31-40, sept. 1987.

GORZ, A. Métamorphoses du travail: Quête du Sens. Critique de la raison économique. Paris: Galilée, 1988.

GORZ, A. Capitalisme, Socialisme, Ecologie: Désorientations, Orientations. Paris: Galilée, 1991.

GORZ, A. Misères du présent: Richesse du possible. Paris: Galilée, 1997.

GORZ, A. Misères du présent. Richesse du posssible. Entretien avec Carlo Vercellone, Patrick Dieuaide et Pierre Péronnet, Alice, n. 1, p. 31-35, sept. 1998,

GORZ, A. L'immatériel: Connaissance, valeur et capital. Paris: Galilée, 2003.

GORZ, A. Richesse sans valeur, valeur sans richesse. Cadernos IHU Ideias, São Leopoldo, n. 31, 2005.

GORZ, A. Penser l'exode de la societé du travail et de la marchandise, Mouvements, [S.l.], v. 50, n. 2, p. 95-106, juin 2007.

GORZ, A. Écologica. Paris: Galilée, 2008.

GORZ, A. Le Fil rouge de l'écologie. Paris: Éditions de l'EHE SS, 2015.

MARX. Karl. Grundrisse: manuscritos econômicos de 1857-185: esboço da crítica da economia política. Supervisão editorial Mário Duayer; tradução Mário Duayer, Nálio Schneider 9colaboração de Alice Helga Werner e Rudiger Hoffman). Boitempo, 2011. 


\section{ANDRÉ GORZ, TOWARDS THE UNCONDITIONALITY OF INCOME}

\author{
Françoise Gollain
}

In keeping with fellow advocates of the guaranteed income, André Gorz considered our present benefit system to be ill-adapted to the volatility and insecurity of the labour market. He held, however, the allocation of an income guaranteed to all, as one of the tools of an emancipatory radical social transformation, well beyond a mere remedy to the dysfunctions of the current system. Such an income should be coupled with two series of measures: reduction of working hours, and the development of 'autonomous activities'. We will consider the importance of these three elements to account for a significant shift in Gorz's works which will lead him to lend his support to a more radical form of universal and unconditional income in his last decade. We will stress that his philosophical and political project remained unchanged throughout this evolution: to undermine the dominance of market-based relationships and progress towards a society characterised by relationships of cooperation.

KEY-words: André Gorz. Existentialism. Unconditionality of basic income.

\section{ANDRE GORZ, VERS LA INCONTIONNALITE DU REVENUE}

Françoise Gollain

André Gorz partageait avec avocats du revenu d'existence le diagnostic selon lequel l'actuel système de redistribution n'est pas adapté à la flexibilité et à la précarisation de l'emploi qui constituent une donnée structurelle du marché du travail. Cependant, au-delà du désir de remédier à ces dysfonctionnements et d'assurer une sécurité existentielle à chacun, il concevait l'octroi d'un revenu garanti à tous comme l'un des instruments d'une transformation sociale radicale et émancipatrice. Dans cette perspective, le revenu d'existence est articulé à deux séries de mesures: réduction du temps de travail et expansion des activités autonomes. L'examen de chacun des termes de ce triptyque nous permettra de rendre compte de l'évolution significative de Gorz vers un degré plus élevé d'inconditionnalité du revenu. Nous nous attacherons à mettre en exergue l'identité de son projet politique (et philosophique) fondamental par-delà ce tournant: faire dépérir les rapports marchands et avancer vers une société caractérisée par de formes de coopération non marchandes.

Mots-Clés: André Gorz. Existencialisme. Incondicionalité du renvenu.

Françoise Gollain - Doutora em Sociologia e Mestra em Filosofia. Professora associada da Open University (Reino Unido). Publicações recentes: Une critique du travail. Entre écologie et socialisme Editions La Découverte (9 Mar. 2000); André Gorz pour une pensée de l'écosocialisme - Le Passager Clandestin (23 April 2014) 
